\title{
Validation and Optimization of Thermophysical Properties for Thermal Conductivity and Viscosity of Nanofluid Engine Oil using Neural Network
}

\author{
Amin Moslemi Petrudi, Masoud Rahmani \\ Department of Mechanical Engineering, Tehran University, Iran \\ * Corresponding author email: amin.moslemi2020@gmail.com
}

Received: 31 January 2020 / Revised: 23 May 2020 / Accepted: 02 June 2020 / Published: 10 June 2020

\begin{abstract}
In this study, the thermophysical properties of thermal conductivity and viscosity of a motor oil nanofluid were investigated using experimental data and artificial neural network. NSGA II optimization algorithm was used to maximize thermal conductivity and minimum viscosity with changes in temperature and volume fraction of nanofluids. Also, to obtain the viscosity and thermal conductivity values in terms of nanofluid temperature and volume fraction with 174 experimental data, neural network modeling was performed. Input data include temperature and volume fraction, and output is viscosity and thermal conductivity. Various indices such as R squared and Mean Square Error (MSE) have been used to evaluate the accuracy of modeling in the prediction of viscosity and thermal conductivity of nanofluids. The coefficient of determination R squared is 0.9989 indicating acceptable agreement with the experimental data. In order to optimize and finally results as an objective function, the optimization algorithm is presented and the Parto front and its corresponding optimum points are presented where the maximum optimization results of thermal conductivity and viscosity occur at $1 \%$ volume fraction.
\end{abstract}

Keywords: Multi-objective Optimization, Nanofluid, Thermal Conductivity, Artificial Neural Network, NSGAII.

\section{Introduction}

Nanofluids have been rapidly attracted to various industries because of their unique thermal conductivity. First coined the term nanofluid, by Choi in 1995 at Argonne Research Institute in the USA, it was used for solid metal particles in the liquid and it was noted that there is a significant difference between the stability and transient properties of these fluids compared to conventional liquid and macro fluid particles [1]. Nano-fluids have been widely used because of their properties, which makes them particularly important to investigate. Also, because these properties depend on the concentration of nanoparticles in the base fluid, by changing the concentration of nanoparticles, the nanofluid properties can be adjusted [2]. Art optimization is about finding the best answer in the current situation. Optimization is used in the design and maintenance of engineering, economic and even social systems in order to minimize the cost and or maximize profits. Optimization methods have been used to increase productivity and reduce costs [3]. The structure and principles of multi-objective optimization are the same as single-objective optimization, but in some ways the number of variables and objective functions in these methods are increased and used to find an optimal solution set rather than an optimal one [4]. Vajjha et al., Conducted studies to determine the thermal conductivity of nanofluids with temperature. The subjects used water / aluminum oxide nanoparticles and water / copper oxide in their experiments. The results of their experiments indicated a direct dependence of thermal conductivity on temperature. The increase in thermal conductivity of water / copper oxide nanofluids was more than that observed in water nanofluids / aluminum oxide. The researchers cited random and irregular movements of nanofluids in the solution as a possible cause of the increase in thermal conductivity, since nanofluids could easily move in the solution [5]. Sabour et al. 
Validation and Optimization of Thermophysical Properties for Thermal Conductivity and Viscosity of Nanofluid Engine Oil .......

Comparative study of Artificial Neural Networks (ANN) and Response Surface Method (RSM) for simultaneous optimization of multiple targets in Fenton treatment of landfill leachate [6]. Zhao et al. investigated the effect of suspended nanofluid size on the thermal conductivity of nanofluids. For this purpose, nanofluids with 36 and $47 \mathrm{~nm}$ diameter nanofluid suspensions (1\% to $6 \%$ by volume of nanofluid fraction) were prepared in water. Concentrations of the specimens were irradiated with ultrasonic waves for 51 minutes. It has been observed that the thermal conductivity of these nanofluids increases with the increase of nanofluid bulk fractions, and the increase in temperature also increases the thermal conductivity of the specimens. Table 1 presents some of the research on the parameters affecting the viscosity and thermal conductivity of nanofluids that have been described and presented using ANN in nanofluids. The use of nanofluids in heat transfer has many advantages such as smaller heat exchangers, improved heat transfer efficiency as well as reduced radiation. More energy can be saved by using nanofluids in the pumping process [7].

Table 1 Research on the viscosity and thermal conductivity of nanofluids

\begin{tabular}{|c|c|c|c|c|}
\hline Author(s) & Nanofluid & Characteristic & Methods & Years \\
\hline Tajik et al.[8] & $\mathrm{Al} 2 \mathrm{O} 3$ & Thermal conductivity & $\begin{array}{l}\text { ANN and } \\
\text { GRG }\end{array}$ & 2017 \\
\hline Ameer et al.[9] & Microwave & $\begin{array}{l}\text { Optimization of } \\
\text { microwave-assisted }\end{array}$ & ANN & 2017 \\
\hline Huang et al.[10] & Ultrasound & Ultrasound-assisted & $\begin{array}{l}\text { RSM and } \\
\text { ANN }\end{array}$ & 2017 \\
\hline Ohale et al.[11] & Alumina & Factor evaluation & $\begin{array}{l}\text { RSM and } \\
\text { ANN }\end{array}$ & 2017 \\
\hline Bagherzadeh et al. [20] & $\mathrm{CuO} /$ liquid & $\begin{array}{l}\text { Optimization/statistical } \\
\text { model composed }\end{array}$ & ANN & 2019 \\
\hline Pordanjani et al [21] & $\begin{array}{c}\text { Magneto- } \\
\text { hydrodynamic }\end{array}$ & $\begin{array}{l}\text { Flow inside a square } \\
\text { enclosure }\end{array}$ & RSM & 2019 \\
\hline Moslemi et al. [22] & Nanotube & $\begin{array}{l}\text { Multi-objective } \\
\text { Optimization }\end{array}$ & RSM & 2020 \\
\hline Moslemi et al. [23] & Water Hybrid & $\begin{array}{l}\text { Thermal Optimization } \\
\text { and Dynamic Viscosity }\end{array}$ & ANN & 2020 \\
\hline
\end{tabular}

In the present study, in order to maximize thermal conductivity and minimum viscosity by varying the temperatures (313 to 333) Kelvin and volume fraction (0 to 1\%) of nanofluid motor oils, laboratory studies and modeling were performed using NSGA II optimization algorithm. The modeling is done using ANN and the results are given as an objective function to the optimization algorithm. Based on the findings of the present study, engine oil nanofluids have not been investigated in vitro by ANN modeling. The nanofluid has been analyzed in volume fractions and at different temperatures and a new relation has been proposed for its viscosity. Experimental data and data obtained from ANN are found to be in good agreement with each other, indicating a high degree of accuracy.

\section{NSGA II Method}

Non-dominated Sorting Genetic Algorithm (NSGAII) is one of the advanced evolutionary algorithms that requires algorithm parameters to be set up in the algorithm shown in Figure 1 below [12].

1. Initialize population (pop-size)

2. Cross over (pc)

3. Mutation (pm)

4. Max iteration (Gen) 


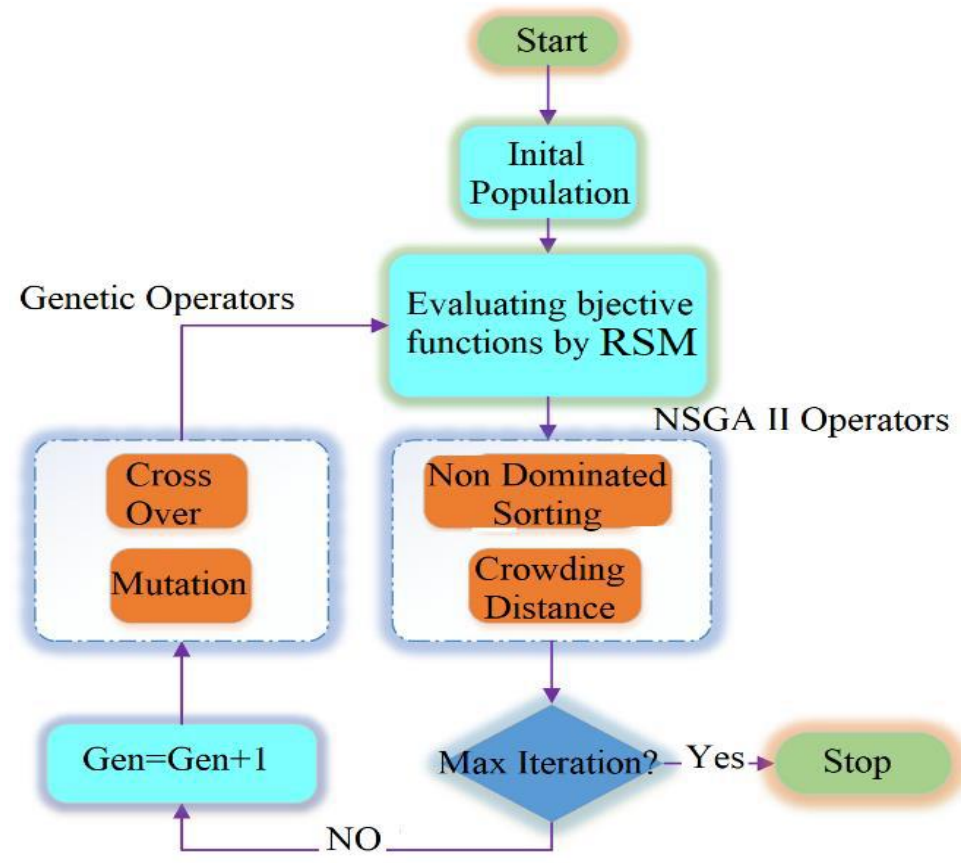

Fig. 1 Display of the optimization algorithm

In this algorithm, the offspring population $(\mathrm{Qt})$ must first be constructed using the parent population (pt) [13]. In this section, instead of using non-dominant offspring solutions, merge $(\mathrm{Qt})$ and $(\mathrm{pt})$ together and form a population of Rt with $2 \mathrm{~N}$ members and then use a non-dominant categorization to categorize the entire population of Rt used, that is, evaluate the current population and divide them into categories with different values [14,15]. The range will be 1 to $2 \mathrm{n}$. And they will form the next generation. Figure 2 shows the structure of the NSGA II network.

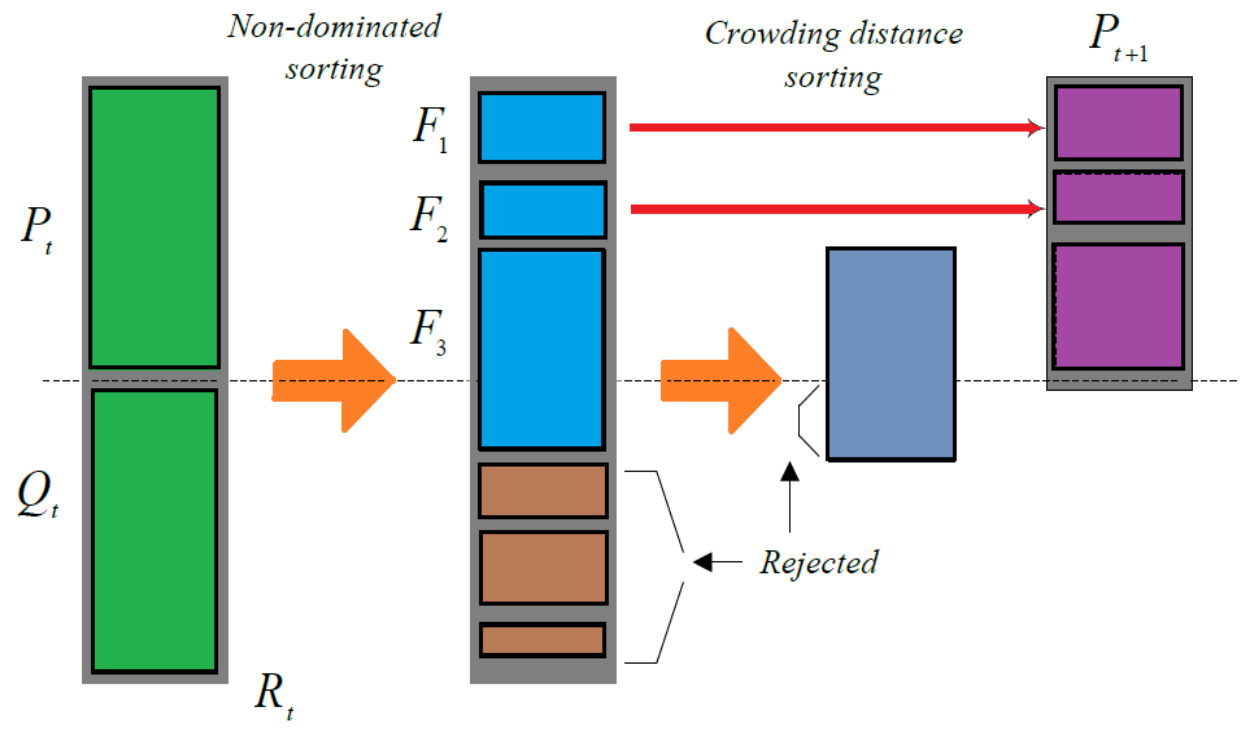

Fig. 2 NSGA II network structure

Answers $i-1$ and $i-2$ the answers before and after are the answer of $\mathrm{i}$, then the distance of the congestion of my answer is as follows:

$d_{i}^{1}=\frac{f_{1}\left(x_{i+1}\right)-f_{1}\left(x_{i-1}\right)}{f_{1}^{\max }-f_{1}^{\min }}$ 


$$
\begin{aligned}
& d_{i}^{2}=\frac{f_{2}\left(x_{i-1}\right)-f_{2}\left(x_{i+1}\right)}{f_{2}^{\max }-f_{2}^{\min }} \\
& d_{i}=d_{i}^{1}+d_{i}^{2}
\end{aligned}
$$

Therefore, in a binary tournament, the answer $i$ is superior to the answer $j$ if either of the following conditions is true:

$>$ Rank $i$ is less than rank $j(r i<r j)$.

$>$ If answer $i$ is equal to $j$ then answer $i$ is superior to answer $j$ if the answer distance $i$ is greater than the answer distance $j(\mathrm{~d} j>\mathrm{dj})$.

A new population of alternatives is formed after the ranking and spacing process, and then by the methods commonly used in genetic algorithms, new populations are generated, new alternatives are generated and then the previous steps are repeated [16,17]. Figure 3 shows the computation of compaction distance in the NSGA II algorithm.

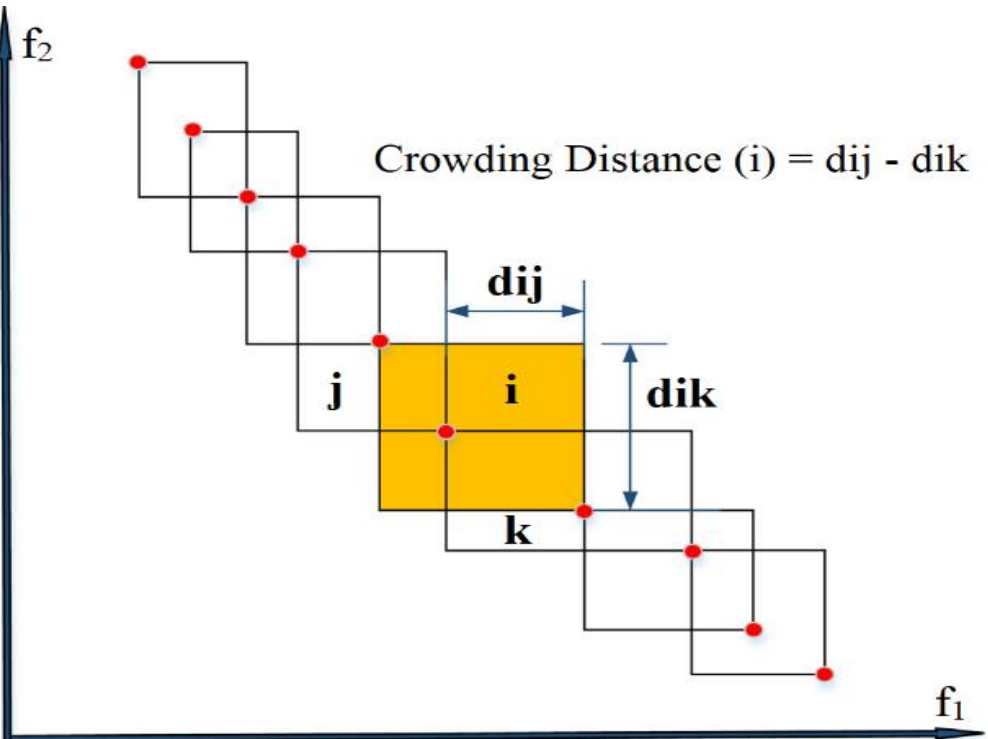

Fig. 3 Computation Distance Compression in NSGA II Algorithm.

\section{Result and discussion}

ANN are systems based on empirical data. The human brain has sets of 1011 living neurons that form a very complex structure of tissues and chemical interactions. Some neural structures have been associated with humans since birth, and others have been formed during human life experiences. Scientists are currently at the forefront of understanding neural networks and have focused solely on how the complex works [18]. According to the discovery, all living neural functions, such as memory, are stored in neurons and in communication between them. Learning means starting a new relation between neurons or changing existing ones. Neural Networks Two basic properties of neural networks include routing and parallelization of the structure and are used extensively in system simulation, especially in nonlinearity. Neural networks in complex systems provide suitable solutions [19]. Figure 4 illustrates a three-layer neural network for modeling viscosity and thermal conductivity. 


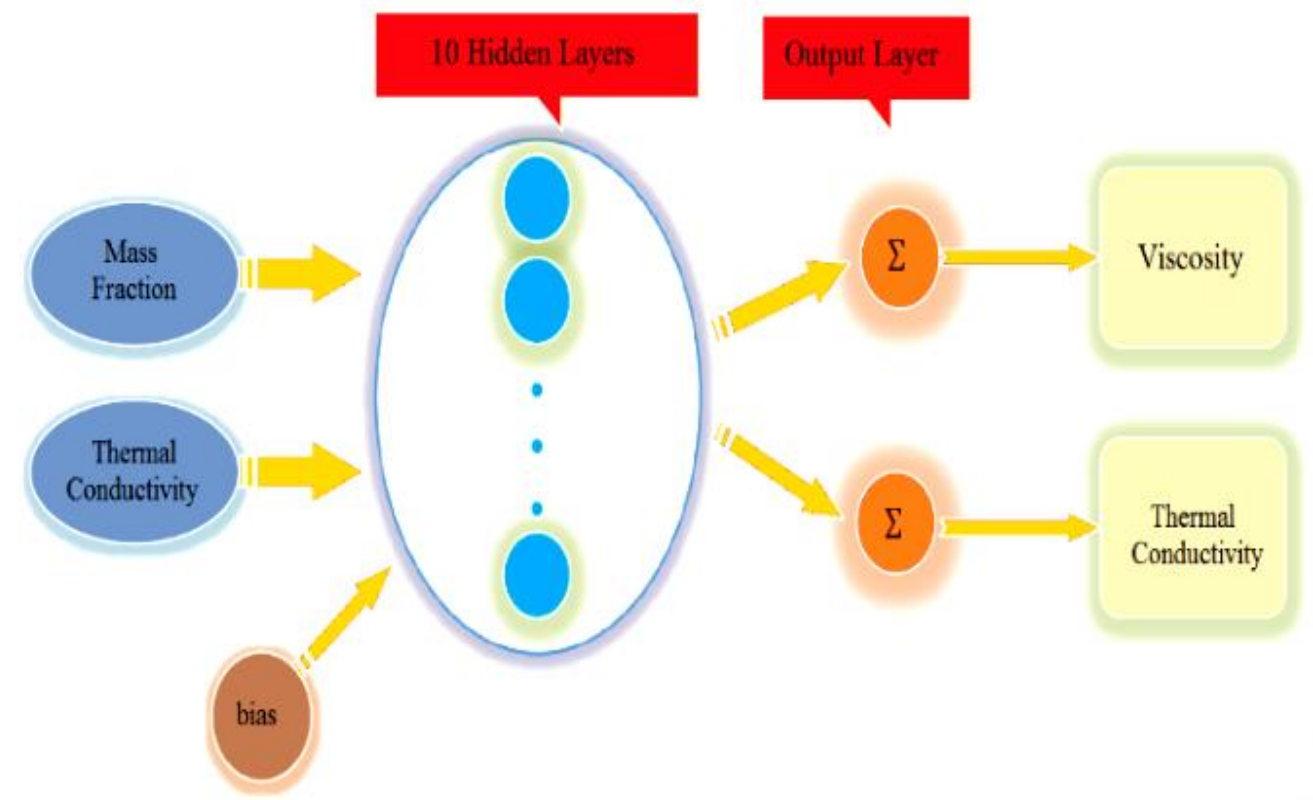

Fig. 4 Three-layer neural network for viscosity modeling and thermal conductivity.

A neural network of 10 neurons in the hidden layer and one neuron in the output layer for viscosity and thermal conductivity models. The number of hidden layer neurons is tentatively determined and given the mean maximum squared error to predict the viscosity and thermal conductivity and provide a comparison between the neural network and the experimental data. The weights and bias are determined by the Levenberg Marquardt algorithm. It should also be noted that the transfer function in the hidden layer of the sigmoid function (logsig) and the linear function (purelin) were performed for the outer layer. Figure 3 and Figure 4 show the mean-squared error for the various data from the viscosity and thermal conductivity ratings. If the MSE value for the evaluation data in a particular iteration is increased, it will fail as results and this iteration process ends when the best result is presented as output [18]. As shown in the figure 5 . diagram of the ANN model for thermal conductivity. Figure 6 shows the performance diagram of the ANN model for viscosity and Figure 7 compares the experimental results of nanofluid viscosity with data from artificial neural network. Figure 8 shows the experimental results of nanofluid thermal conductivity with data from artificial neural network.

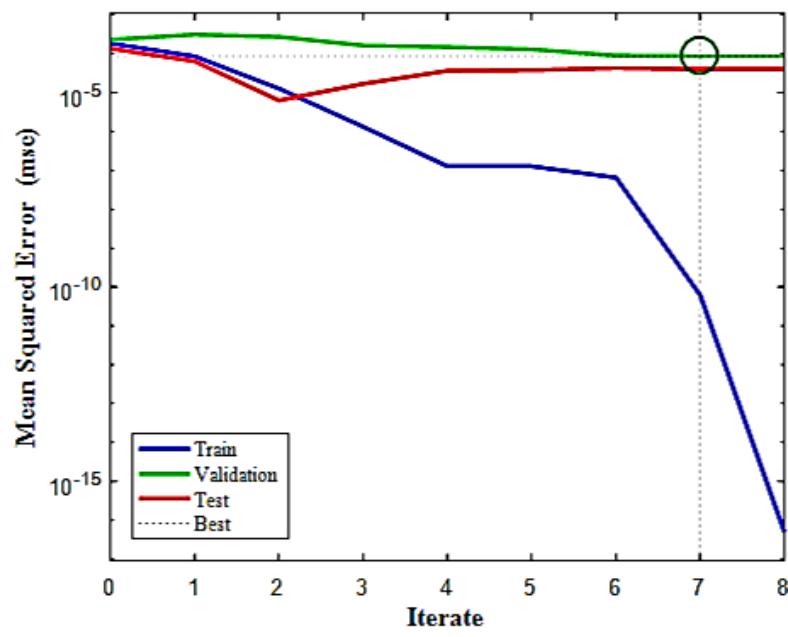

Fig. 5 ANN model performance diagram for thermal conductivity

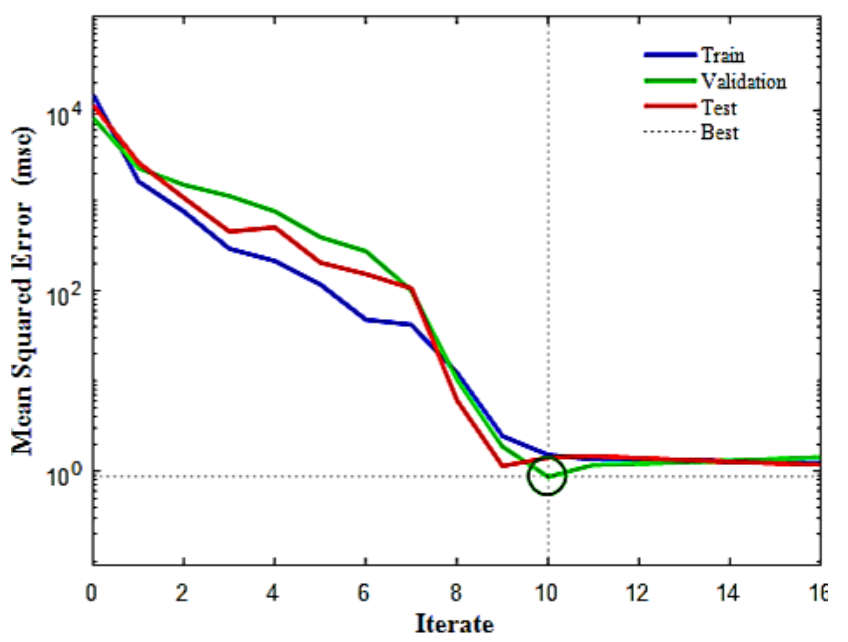

Fig. 6 ANN model performance diagram for viscosity 
Validation and Optimization of Thermophysical Properties for Thermal Conductivity and Viscosity of Nanofluid Engine Oil ........

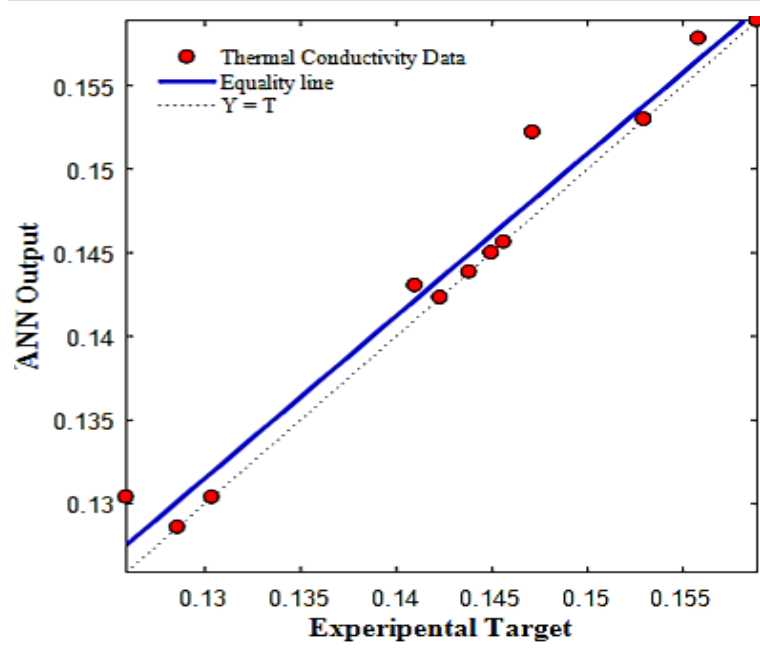

Fig. 7 Comparison of experimental results of nanofluid thermal conductivity with data ANN

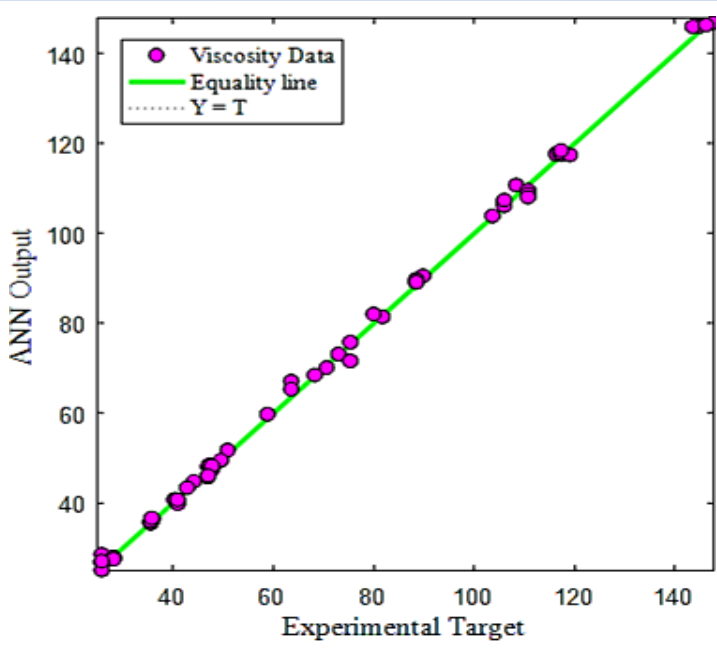

Fig. 8 Comparison of experimental results of nanofluid viscosity with data ANN

Based on the modeling performed on the experimental results of engine oil nanofluid, the modeling parameters for the best network response are reported in Table 2. The value of regression coefficient is 0.9989 which is an acceptable value for data modeling. MSE shows for Mean Squared Error and MAE shows for Mean Absolute Error, and RC shows for Regression Coefficient.

Table 2 Results of ANN

\begin{tabular}{cccccc}
\hline MSE & MAE & $\begin{array}{c}\text { Test } \\
\text { performance }\end{array}$ & $\begin{array}{c}\text { Train } \\
\text { performance }\end{array}$ & $\begin{array}{c}\text { Valid } \\
\text { performance }\end{array}$ & RC \\
\hline $\begin{array}{c}5.57 \mathrm{e}- \\
06\end{array}$ & 0.0041 & $1.83 \mathrm{e}-05$ & $3.25 \mathrm{e}-06$ & $4.47 \mathrm{e}-06$ & 0.9989 \\
\hline
\end{tabular}

In order to obtain the Algorithm optimal results of the algorithm in several steps with different values of 50 members of population and 20 times iterations. As shown in Figure 9 to compare the results of the optimization process on the first, fifth, tenth and Pareto optimization fronts. Figure 10 it shows the Pareto fronts. Using the optimization obtained, thermal conductivity from 313 to $333^{\circ} \mathrm{C}$ can be used. In each generation of optimization, the optimized values are compared to the previous generation and finally the best results are presented which shows the accuracy of the performance of the optimization algorithm. Optimal points of thermal conductivity and viscosity equivalent to it can be obtained by means of the curve.

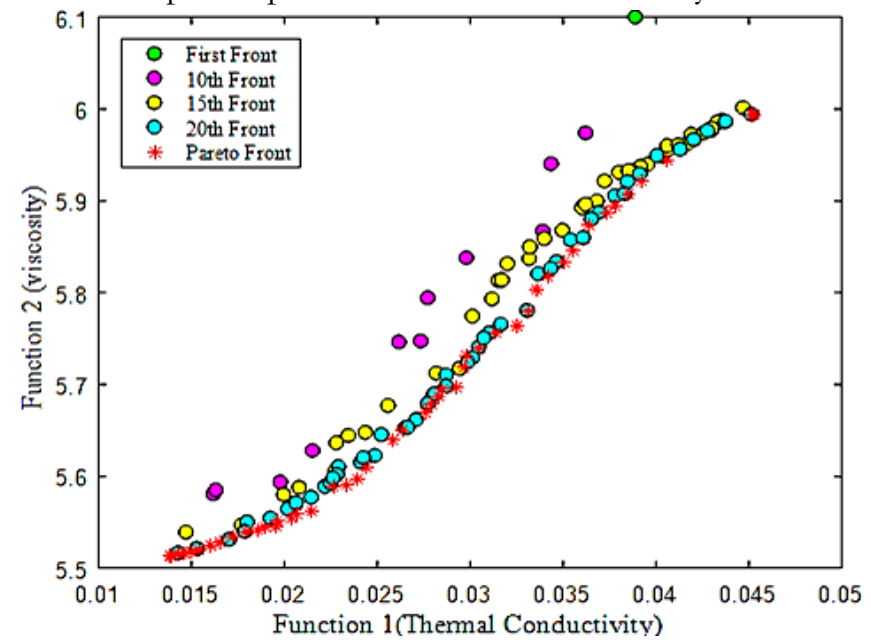

Fig. 9 Multi-objective optimization results using NSGA II

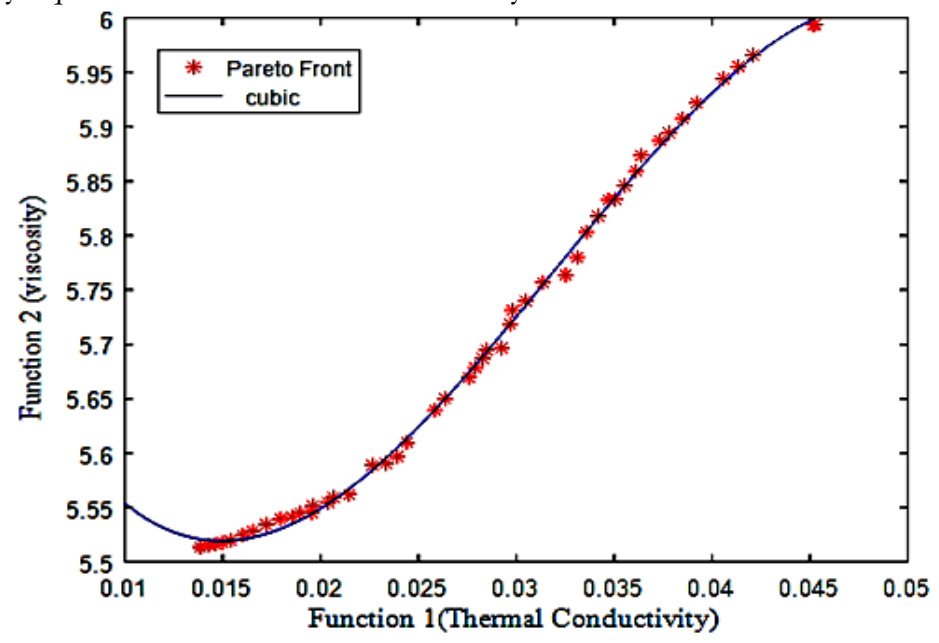

Fig. 10 Pareto optimal front 
Amin Moslemi Petrudi et al., J. Mod. Sim. Mater.; Vol. 3 Issue 1, pp: 53-60, 2020

To obtain the optimal point pattern with ANN estimation function for maximum thermal conductivity coefficient (3) is presented which can be used to obtain the desired minimum viscosity for the specified thermal conductivity.

New Experiment Relation

$$
\begin{aligned}
& \text { Viscosity }=-25250 x^{3}+2418 / 7 x^{2}-55 / 325 x+5 / 8903 \\
& \mathrm{X}=\text { Thermal Conductivity } \\
& \text { Norm of Residuals }=0.04123
\end{aligned}
$$

\section{Conclusion}

In the present study, was to optimize nanofluid to reduce viscosity and increase thermal conductivity. The optimization was performed by determining the objective functions, experimental viscosity data, thermal conductivity of nanofluid and applying ANN. The neural network structure was performed by generating temperature input data and volume fraction to determine thermal conductivity and viscosity. After objective variables and functions defined in NSGA II method, multi-objective optimization was performed. And the viscosity and thermal conductivity solutions are presented on the Pareto front. The results show the highest thermal conductivity and the lowest viscosity when the maximum temperature point is $333^{\circ} \mathrm{C}$ and the volume fraction is 0 until the 1 . Among the results, the points with the highest thermal conductivity and the lowest viscosity were selected as the best point.

\section{Competing Interests}

The authors declared that no conflict of interest exist in this publication.

\section{How to Cite this Article:}

A. Moslemi Petrudi and M. Rahmani, "Validation and Optimization of Thermophysical Properties for Thermal Conductivity and Viscosity of Nanofluid Engine Oil using Neural Network", J. Mod. Sim. Mater., vol. 3, no. 1, pp. 53-60, Jun. 2020. https://doi.org/10.21467/jmsm.3.1.53-60

\section{References}

[1] S. Lee, S. SU, S. Choi, J. Li, A. Eastman. "Measuring thermal conductivity of fluids containing oxide nanoparticles." Journal Heat Transfer (1999): 280-289. https://doi.org/10.1115/1.2825978

[2] A. Esmaeeli, M. Pouladian, A. Monfared, S. R. Mahdavi, D. Moslemi. "A Genetic Algorithm and Neural Network Hybrid Model to Predict Lung Radiation-Induced Pneumonitis in Breast Radiotherapy (A simulation Study)." Journal of Babol University of Medical Sciences 16, no. 1 (2014): 77-84. http://jbums.org/article-1-4614-en.html

[3] M. H. Esfe, H. Hajmohammad, R. Moradi, A. A. Abbasian. "Multi-objective optimization of cost and thermal performance of double walled carbon nanotubes/water nanofluids by NSGA-II using response surface method." Applied Thermal Engineering. 112 (2017): 1648-1657. https://doi.org/10.1016/j.applthermaleng.2016.10.129

[4] S.Shriram, V. Juwar. "Optimization of conditions for an enhancement of thermal conductivity and minimization of viscosity of ethylene glycol based $\mathrm{Fe} 3 \mathrm{O} 4$ nanofluid." Applied Thermal Engineering. $109 \quad$ (2016): 121-129. https://doi.org/10.1016/j.applthermaleng.2016.08.066

[5] V., Ravikanth, D. Das. "Experimental determination of thermal conductivity of three nanofluids and development of new correlations." International Journal of Heat and Mass Transfer 52, no. 21-22 (2009): 4675-4682. https://doi.org/10.1016/j.ijheatmasstransfer.2009.06.027

[6] M. R. Sabour, A. Amiri. "Comparative study of ANN and RSM for simultaneous optimization of multiple targets in Fenton treatment of landfill leachate." Waste management 65 (2017): 54-62. https://doi.org/10.1016/j.wasman.2017.03.048

[7] N. Zhao, L. Zhiming. "Experiment and artificial neural network prediction of thermal conductivity and viscosity for alumina-water nanofluids." Materials 10, no. 5 (2017): 552. https://doi.org/10.3390/ma10050552

[8] J. Tajik, A. H. Zamzamian. "Optimization of thermal conductivity of A12O3 nanofluid by using ANN and GRG methods." International Journal of Nanoscience and Nanotechnology 9, no. 4 (2013): 177-184. http://www.ijnnonline.net/article_4165.html

[9] K. Ameer, J. Yunhee, L. Hyun-Gyu, A. Ameer, J. Kwon. "Optimization of microwave-assisted extraction of total extract, sativoside and rebaudioside-A from Stevia rebaudiana (Bertoni) leaves, using response surface methodology (RSM) and artificial neural network (ANN) modelling." Food chemistry 229 (2017): 198-207. https://doi.org/10.1016/j.foodchem.2017.01.121

[10] H. Shang-Ming, K. Chia-Hung, C. Chun-An, L. Yung-Chuan, J. Chwen. "RSM and ANN modeling-based optimization approach for the development of ultrasound-assisted liposome encapsulation of piceid." Ultrasonic sonchemistry 36 (2017): 112-122. https://doi.org/10.1016/j.ultsonch.2016.11.016 
[11] P. Ohale, F. Uzoh, O. Onukwuli. "Optimal factor evaluation for the dissolution of alumina from Azaraegbelu clay in acid solution using RSM and ANN comparative analysis." south African journal of chemical engineering 24 (2017): 43-54. https://doi.org/10.1016/j.sajce.2017.06.003

[12] S. Yandamuri, K. Srinivasan, S. Bhallamudi. "Multi objective optimal waste load allocation models for rivers using non dominated sorting genetic algorithm-II." Journal of water resources planning and management 132, no. 3 (2006): 133-143. https://doi.org/10.1061/(ASCE)0733-9496(2006)132:3(133)

[13] M. Esfe, M. Hajmohammad, P. Razi, M.R. Hassani, A. A. Abbasian. "The optimization of viscosity and thermal conductivity in hybrid nanofluids prepared with magnetic nanocomposite of Nano diamond cobalt-oxide (ND-Co3O4) using NSGA-II and RSM." International Communications in Heat and Mass Transfer 79 (2016): 128-134. https://doi.org/10.1016/j.icheatmasstransfer.2016.09.015

[14] W. Xinwei, X. Xianfan, C. Stephen. "Thermal conductivity of nanoparticle-fluid mixture." Journal of thermo physics and heat transfer 13, no. 4 (1999): 474-480. https://doi.org/10.2514/2.6486

[15] P. Hrishikesh, D. Sarit. T. Sundararajan, A. Sreekumaran, T. Pradeep. "Thermal conductivities of naked and monolayer protected metal nanoparticle based nanofluids: Manifestation of anomalous enhancement and chemical effects." Applied Physics Letters 83, no. 14 (2003): 2931-2933. https://doi.org/10.1063/1.1602578

[16] M. Esfe, S. Esfandeh, S. Saedodin, H. Rostamian. "Experimental evaluation, sensitivity analyzation and ANN modeling of thermal conductivity of ZnO-MWCNT/EG-water hybrid nanofluid for engineering applications." Applied Thermal Engineering 125 (2017): 673-685. https://doi.org/10.1016/j.applthermaleng.2017.06.077

[17] M. Esfe, S. Saedodin, M. Mahmoodi. "Experimental studies on the convective heat transfer performance and thermophysical properties of $\mathrm{MgO}-$ water nanofluid under turbulent flow." Experimental thermal and fluid science 52 (2014): 68-78. https://doi.org/10.1016/j.expthermflusci.2013.08.023

[18] M. Esfe, S. Saedodin, A. Naderi, A. Alirezaie, A. Karimipour, S. Wongwises, M. Goodarzi, M. Dahari. "Modeling of thermal conductivity of ZnO-EG using experimental data and ANN methods." International Communications in Heat and Mass Transfer 63 (2015): 35-40. https://doi.org/10.1016/j.icheatmasstransfer.2015.01.001

[19] M. Esfe, P. Razi, M. H. Hajmohammad, H. Rostamian, W. Sarsam, A. Abbasian, M. Dahari. "Optimization, modeling and accurate prediction of thermal conductivity and dynamic viscosity of stabilized ethylene glycol and water mixture A12O3 nanofluids by NSGAII using ANN." International Heat and Mass Transfer 82 (2017): 154-160. https://doi.org/10.1016/j.icheatmasstransfer.2016.08.015

[20] Bagherzadeh, Seyed Amin, Mohsen Tahmasebi Sulgani, Vahid Nikkhah, Mehrdad Bahrami, Arash Karimipour, and Yu Jiang. "Minimize pressure drop and maximize heat transfer coefficient by the new proposed multi-objective optimization/statistical model composed of" ANN+ Genetic Algorithm" based on empirical data of CuO/paraffin nanofluid in a pipe." Physica A Statistical Mechanics and its Applications 527 (2019): 121056. https://doi.org/10.1016/j.physa.2019.121056

[21] Pordanjani, Ahmad Hajatzadeh, Seyed Masoud Vahedi, Farhad Rikhtegar, and Somchai Wongwises. "Optimization and sensitivity analysis of magneto-hydrodynamic natural convection nanofluid flow inside a square enclosure using response surface methodology." Journal of Thermal Analysis and Calorimetry 135, no. 2 (2019): 1031-1045. https://doi.org/10.1007/s10973-018-7652-6

[22] A. Moslemi Petrudi, P. Fathi, and M. Rahmani, "Multi-objective Optimization to Increase Nusselt Number and Reduce Friction Coefficient of Water/Carbon Nanotubes via NSGA II using Response Surface Methodology”, J. Mod. Sim. Mater., vol. 3, no. 1, pp. 1-14, Mar. 2020. https://doi.org/10.21467/jmsm.3.1.1-14

[23] Petrudi, Amin Moslemi, and Ionut Cristian Scurtu. "Investigating and Modeling the Factors Affecting Thermal Optimization and Dynamic Viscosity of Water Hybrid Nanofluid/Carbon Nanotubes via MOPSO using ANN." Technium: Romanian Journal of Applied Sciences and Technology 2, no. 3 (2020): 108-114. https://www.techniumscience.com/index.php/technium/article/view/575

Publish your research article in AIJR journals-

* Online Submission and Tracking

* Peer-Reviewed

* Rapid decision

* Immediate Publication after acceptance

* Articles freely available online

* Retain full copyright of your article

Submit your article at journals.aijr.in
Publish your books with AIJR publisher-

* Publish with ISBN and DOI.

* Publish Thesis/Dissertation as a Book.

* Publish Monograph.

* Publish Edited Volume/ Book.

* Publish Conference Proceedings

- Retain full copyright of your books.

Submit your manuscript at books.aijr.org 